\title{
IDENTIFICAÇÃO DE PROBLEMAS DO CURRÍCULO, DO ENSINO E DA APRENDIZAGEM DE FÍSICA E DE MATEMÁTICA A PARTIR DO DISCURSO DE PROFESSORES ${ }^{1}$ Identifying curriculum, teaching and physics and mathematics learning problems from teachers discourse
}

\author{
Flavia Rezende \\ Arilise M oraes de Almeida Lopes \\ Jeanine M aria Egg
}

\begin{abstract}
Resumo: 0 contexto deste estudo é o desenvolvimento de um ambiente virtual construtivista para a formação continuada de professores de Física e de M atemática do nível médio, cujo objetivo é promover o desenvolvimento do conhecimento profissional do professor a partir da reflexão sobre problemas autênticos da sua prática. No presente estudo, buscou-se a autenticidade dos problemas no discurso de uma amostra de professores de escolas públicas do município do Rio de Janeiro e do interior do Estado. A análise de conteúdo permitiu a classificação do discurso dos professores em três categorias: Condições Estruturais da escola pública, Currículo e Ensino-A prendizagem. A partir da análise de avaliação dos temas que compõe as categorias Currículo e EnsinoAprendizagem, foi identificada uma série de problemas comuns a professores de Física e de M atemática da escola pública. 0 s problemas curriculares estão marcados pel as políticas educacionais atuais e os de ensino-aprendizagem dizem respeito tanto a aspectos teóricos quanto a práticos do trabalho dos professores além de exprimirem queixas em relação às deficiências de vários tipos do aluno da escola pública.
\end{abstract}

Unitermos: problemas da prática pedagógica, ensino de Física, ensino de M atemática.

\begin{abstract}
A virtual constructivist learning environment is being developed for in-service education of Physics and M athematics teachers. Its instructional design is based on Problem Based Learning with the main goal of promoting reflection about authentic professional problems. The present study looked for the authenticity of the problems in the discourse of a group of teachers who work in public schools of the capital of Rio de Janeiro State and other towns of the north of the State. The content analysis of their discourse allowed its classification into three categories: Structural Conditions of the Public School, Curriculum, and Teaching. The evaluation analysis of the themes that compose the categories of Curriculum and Teaching led to the identification of similar problems that teachers of Physics and of $M$ athematics deal with in public schools. The problems related to the curriculum are influenced by educational policies and those related to teaching refer to practical and theoretical aspects of their work besides the expression of discontent with different types of deficiencies in pupils.
\end{abstract}

Keywords: problems of pedagogical practice, teaching of Physics, teaching of M athematics.

\footnotetext{
${ }_{1}^{1}$ Parte desta pesquisa foi apresentada no IV Encontro N acional de Pesquisa em Educação em Ciências, Bauru, 2003. Apoio: CN Pq.

2 Professora adjunta do N úcleo de Tecnologia Educacional para a Saúde da U niversidade Federal do Rio de Janeiro (email: flaviarezende@uol.com.br).

${ }^{3}$ M estrandas do Programa de Pósgraduação do Núcleo de Tecnologia Educacional para a Saúde da Universidade Federal do Rio de Janeiro.
} 


\section{0 contexto}

0 contexto deste estudo é o desenvolvimento de um ambiente virtual construtivista (Jonassen, 1996, Jonassen, 1998, Struchiner et al., 1998) para a formação continuada de professores de Física do nível médio (Rezende et al., 2003) denominado de InterAge. ${ }^{4} \mathrm{Um}$ ambiente de aprendizagem moldado pela perspectiva construtivista tem como premissa básica colocar o aluno no controle do processo de aprendizagem (Rezende, 2000). Em linhas gerais, o desenho instrucional do InterAge tem como princípios estimular a reflexão-sobreaação (Schön, 2000), promover a interatividade e incentivar a colaboração entre os participantes de modo a desenvolver o conhecimento profissional do professor (Porlán e Rivero, 1998). A metodologia usada para concretizar estes princípios é a A prendizagem Baseada em Problemas (ABP) (Barrows e Tamblyn, 1980, Savery e D uffy, 1995), considerada adequada para inverter a vertical ização do processo de entrega de informações aos professores e fazer com que o professor possa refletir, repensar e criar a sua prática pedagógica ao resolver problemas relevantes e autênticos em relação à sua realidade com base em recursos pedagógicos ${ }^{5}$ e recursos de comunicação on-line.

A ABP surgiu no cenário educacional dos anos 50, na educação médica, na Universidade de M CM aster, C anadá, disseminando-se, posteriormente, para universidades nos EU A, Europa e também para o Brasil (Komatsu et al., 1998) e para outras áreas do conhecimento como Administração, Educação, Arquitetura, Direito, Engenharia e Serviço Social (Savery e Duffy, 1995). Essa metodologia procura substituir o modelo tradicional de transmissão de conhecimentos por um outro modelo voltado para o desenvolvimento das habilidades necessárias para a resolução de problemas reais que o estudante poderá enfrentar em sua futura prática profissional. 0 problema passa a ser, então, o estímulo para toda a aprendizagem subseqüente e ativador de conhecimentos prévios a respeito do tema ( $\mathrm{H}$ ilgard e Bower, 1975, citado por Caprara, 2001) não sendo, em geral, necessária exposição formal prévia de informação aos alunos (Komatsu et al., 1998).

0 objetivo da ABP pode ser aproximado à estratégia formativa designada como sala de espelhos proposta por Schon (2000), segundo a qual profissionais são levados a analisar situações simuladas que espelhem as situações reais usualmente vivenciadas e a problematizar e redimensionar sua prática. Ao refletir sobre sua própria prática, o professor converte-se em um investigador da sala de aula, produzindo saberes pedagógicos, situando a temática em uma nova epistemologia da prática (Schnetzler, 2000). Esta não desconsidera contribuições teóricas advindas da pesquisa acadêmica, nos moldes da racionalidade técnica, mas pressupõe sua integração aos problemas da prática para possibilitar a reflexão sobre ela e o planejamento, a implementação e a avaliação de reformulações da mesma.

M as, o que são problemas? Problemas resultam de qualquer situação na qual um indivíduo procura satifisazer uma necessidade ou realizar um objetivo. N o entanto, esta situação só

\footnotetext{
${ }^{4}$ Trata-se de um website que reúne um conjunto de páginas sob a U RL http://nutes2.nutesufrj.br/interage. 0 nome InterAge foi escol hido por evocar dois conceitos que fazem parte do desenho instrucional do ambiente: a Interação, que diz respeito às interações on-line professor-professor e professor-tutor, e a Ação, que se relaciona ao fato do aluno poder construir algo relativo à sua prática a partir da reflexão. Para chamar atenção para esses dois aspectos, o nome é grafado InterAge.

${ }^{5}$ Recursos pedagógicos são trabal hos publicados, resumos do conteúdo de materiais educativos como textos, pôsteres, softwares e vídeos educativos de domínio público e sugestões para sua utilização, solução de uma situação-problema propos ta por especialistas e links que são endereços de sites apresentados por um resumo do seu conteúdo. 0 Inter Age está sendo ampliado visando também à formação de professores de $M$ atemática, o que significa a inclusão de problemas e de recursos pedagógi cos relativos ao ensino de M atemática.
} 
Identificação de problemas do currículo, do ensino e da aprendizagem...

se constituirá de fato num problema quando houver uma "necessidade sentida" (Arlin, 1989, citado por Jonassen, 1997) que motiva as pessoas a buscarem uma solução para eliminar discrepâncias.

Jonassen (1997) situa os problemas em um continum, cujas extremidades seriam os problemas muito estruturados e os pouco estruturados. 0 s problemas muito estruturados são descontextualizados e admitem soluções convergentes, como o cálculo da solução para uma determinada equação matemática, por exemplo. Os problemas pouco estruturados, ao contrário, são aqueles muito contextualizados, que dão margem a incertezas sobre os conceitos ou princípios necessários para solucioná-los e admitem múltiplas soluções, como seria o caso do planejamento de uma estratégia didática para determinado problema pedagógico. Esses são os que interessam para a ABP porque estão situados na realidade cotidiana e, por isso, têm significado para os alunos (Jonassen, 1997), que são solicitados a defini-los melhor e a determinar as informações e processos envolvidos na sua proposta de solução.

$\mathrm{Na}$ ABP aplicada à área da Saúde, os problemas propostos aos al unos podem ser elaborad os a partir de dados registrados em fichas de pacientes. Entretanto, na área da Educação, não há mecanismos que facilitem o registro dos problemas enfrentados pelos professores na sua prática profissional. Sua suposta autenticidade fica, então, a cargo da equipe responsável pelo desenvolvimento do currículo ou dos ambientes virtuais construtivistas, que os elabora.

$\mathrm{N}$ este estudo, buscou-se no discurso de professores a autenticidade dos problemas a serem propostos aos professores-usuários do InterAge. Para tal, uma amostra de professores foi investigada com o objetivo de se delinear a percepção que esses professores têm de sua prática pedagógica e identificar os principais problemas enfrentados por eles.

\section{A prática pedagógica de professores das Ciências}

Vários autores têm se dedicado a compreender a prática docente do professor de ciências. Para Porlán e Rivero (1998), esta prática traduz o conhecimento profi ssional do professor necessário à ação docente. Segundo os autores, este conhecimento não é apenas acadê mico, na medida em que leva em consideração problemas relacionados à intervenção; não pode ser considerado como um conjunto de competências técnicas, pois se refere a processos humanos; e não pode basear-se na simples interiorização acrítica da experiência quando busca coerência e rigor.

Segundo Ponte (1998), o conhecimento profissional docente é essencialmente orientado para a ação e se desdobra em quatro grandes domínios: "(i) o conhecimento dos conteúdos de ensino, incluindo as suas inter-relações internas e com outras disciplinas e as suas formas de raciocínio, de argumentação e de validação; (ii) o conhecimento do currículo, incluindo as grandes finalidades e objetivos e a sua articulação vertical e horizontal; (iii) o conhecimento do aluno, dos seus processos de aprendizagem, dos seus interesses, das suas necessidades e dificuldades mais freqüentes, bem como dos aspectos culturais e sociais que podem interferir positiva ou negativamente no seu desempenho escolar; e (iv) o conhecimento do processo instrucional, no que se refere à preparação, condição e avaliação da sua prática letiva" (p. 61).

Este conhecimento, longe de estar isolado, relaciona-se de um modo muito estreito com o contexto (da escola, da comunidade, da sociedade) e com o conhecimento que o professor tem de si mesmo (Ponte, 1998). Somam-se a este conhecimento as concepções implícitas e explícitas sobre diferentes variáveis relacionadas com o ensino (como, por exemplo, a concepção de ciência, ensino, aprendizagem e currículo) que os professores têm e que não mudam automaticamente quando confrontadas com perspectivas diferentes (Porlán e Rivero, 1998). 
Estas concepções, muitas vezes, se constroem na experiência que o professor teve como aluno, na formação inicial, pertencendo ao senso comum a idéia de que "professores ensinam como eles foram ensinados" (G ibson, 2000, Graeber et al., 2001). Isto implica que o processo de formação (tanto a inicial quanto a continuada) não pode ser apenas a apresentação de conteúdos e de um repertório de abordagens de ensino, mas que precisa incluir necessariamente a discussão das concepções do professor e dos problemas de sua prática.

Trata-se de promover um saber prático intermediário entre a teoria e a ação e da reformulação crítica dos saberes de natureza epistemológica diferente (saberes acadêmicos; saber cotidiano próprio, carregado de ideologia e de valores; saber proveniente da experiência, etc.) através de um processo não-linear em que se devem alternar momentos de reflexão, de estudos e experimentação (D evelay, 1983, citado por Porlán e Rivero, 1998).

Q uestões metodológicas, juntamente com as curriculares e às referentes aos processos de avaliação, têm sido alvo de cursos de formação continuada, por constituírem o centro da ação profissional docente e refletirem o conjunto de concepções e crenças implícitas ou explícitas do professor (Kruger, 2001) sobre a natureza da ciência, sobre o ensino de Ciências, sobre a aprendizagem científica e sobre as dimensões do currículo de Ciências (Porlán e Rivero, 1998).

Porlán e Rivero (1998) apontam os seguintes obstáculos e dificuldades em relação à prática pedagógica de professores das Ciências: (i) a escassa integração de diferentes tipos de conhecimentos (científicos, sociais, pessoais, metadisciplinares, etc.) na formulação dos conteúdos; (ii) o grau de flexibilidade do plano de atividades, por vezes muito detalhado, fechado e rígido e em outro extremo, pouco detalhado e totalmente aberto; (iii) a visão simplificadora da avaliação entendida ora como uma medição objetiva do grau de entendimento acadê mico dos alunos ora como uma impressão subjetiva sobre as atitudes e o esforço do aluno.

Para promover a reflexão dos professores, estes obstáculos são traduzidos nas seguintes questões: o que sabemos nós, os professores, sobre determinados tópicos curriculares? 0 que sabem nossos alunos a respeito de alguns tópicos determinados? Como podemos detectar as idéias dos al unos? Q ue finalidades educativas deveriam ter a escola básica? 0 que ensinar a nossos al unos de um tópico concreto? Como ensinar a nossos alunos um conteúdo concreto? Q ue dados devemos coletar e como fazer para obter informação significativa do desenvolvimento de uma determinada intervenção curricular? A partir destas questões, são propostas atividades que levam os professores a superar as dificuldades e a elaborar seu modelo didático pessoal.

Também têm sido apontadas dificuldades de se promoverem mudanças coletivas na prática docente, principalmente devido às regras impostas pela direção da escola, pelo currículo ou pelas políticas educativas (Allain, 2000, citado por Menezes e Vaz, 2002). $D$ ificuldades para implementar estratégias que incluam materiais didáticos diferentes do livrotexto, especialmente equipamentos de laboratório e as tecnologias da informação e comunicação vêm, se constituindo em problemas da prática pedagógica de professores das ciências (Vianna e Araújo, 2002).

\section{D esenho do estudo}

Este estudo se caracteriza como qualitativo na medida em que se trabalhou com a interpretação do discurso dos sujeitos. Foram realizadas entrevistas não diretivas com 18 professores de Física de oito escolas da rede pública de diferentes bairros do município do Rio de Janeiro e com 22 professores de M atemática de dez escolas de municípios da região N orte e N oroeste fluminense (municípios de Bom Jesus de Itabapuana, Campos dos Goytacazes, Italva, Itaperuna e M acaé). Foi usado um protocolo (quadro 1) que propõe questões gerais sobre a prática pedagógica e temas específicos em função do panorama educacional de hoje, 
Identificação de problemas do currículo, do ensino e da aprendizagem...

como por exemplo, as inovações curriculares propostas pelos Parâmetros Curriculares N acionais (PC N s) (Brasil, 1998) e a introdução das tecnologias da informação e comunicação no ensino, para que os professores discorressem a respeito e assim fosse possível explorar a percepção que os professores têm de sua prática pedagógica, de suas dificuldades e dos problemas enfrentados. Assim, as entrevistas tiveram o objetivo de levar o professor a avaliar aspectos gerais do currículo, do ensino e da aprendizagem dos alunos, não tendo sido exploradas questões pedagógicas relacionadas especificamente a determinado conteúdo.

\section{Q uadro 1: protocolo usado para as entrevistas}

\begin{tabular}{|c|c|}
\hline Q uestões abertas & Temas específicos \\
\hline Como você avalia sua prática pedagógica? & Inovações curriculares \\
\hline $\begin{array}{c}\text { Como você avalia a aprendizagem } \\
\text { de seus alunos? }\end{array}$ & $\begin{array}{c}\text { Tecnologias da Informação e } \\
\text { Comunicação no ensino }\end{array}$ \\
\hline
\end{tabular}

A partir de um contato das pesquisadoras com a direção de cada uma das escolas, foram marcados horários para a realização de entrevistas com pelo menos dois professores (um de Física e um de M atemática) dos que se dispuseram a participar do estudo.

\section{Procedimentos de análise}

As entrevistas, realizadas em um período médio de 45 minutos, foram gravadas com auxílio de um minigravador e as fitas posteriormente transcritas. A análise de conteúdo (Bardin, 1977) do discurso dos professores permitiu levantar os principais temas e identificar problemas da prática pedagógica enfrentados por eles. Este processo envolveu três fases: a pré análise; a exploração do material; e a análise e interpretação dos resultados.

$\mathrm{N}$ a pré-análise foi realizada uma leitura flutuante do material para, de acordo com o objetivo e questões de estudo, definir a unidade de registro ou índice. Esta unidade foi entendida como uma unidade de significação a ser codificada visando a categorização. U tilizou-se o tema como unidade de registro por ser a unidade considerada adequada a estudos que envolvem atitudes, valores, opiniões e percepç̃es.

$\mathrm{Na}$ fase de exploração do material, foi realizado o processo de codificação pelo recorte dos textos em temas, os quais foram enumerados para se chegar a uma correspondência entre a sua presença/ausência e os significados inferidos. 0 critério para a inclusão de um tema não foi quantitativo, mas a presença do mesmo no discurso do professor. O s temas foram classificados e reagrupados permitindo a construção de um sistema de categorias baseado no significado dos mesmos.

A fase de análise e interpretação dos resultados caracterizou-se pelas inferências e interpretações realizadas a partir da análise de avaliação (Bardin, 1977) cujo objetivo foi interpretar a carga avaliativa atribuída pelos professores aos temas levantados na etapa anterior, identificando-se assim os problemas da prática pedagógica. Para isso, foram considerados somente os enunciados que exprimissem uma avaliação ou atitude ${ }^{6}$ dos professores entrevistados em relação à sua prática.

\footnotetext{
${ }^{6}$ Para Bardin (1977), uma atitude é uma prédisposição (favorável ou deffavorável) para reagir sob forma de opiniões
} ou de atos em presença de pessoas, idéas ou acontecimentos. 


\section{Aprendizagem \\ 0 discurso dos professores: Condições Estruturais, Currículo e Ensino-}

O s temas extraídos da análise do discurso dos professores entrevistados foram agrupados semanticamente segundo as categorias "Condições Estruturais", "Currículo" e "EnsinoAprendizagem", conforme apresentado no quadro 2.

A categoria "Condições Estruturais" diz respeito a um conjunto de significações manifestas no discurso dos professores sobre as condições de trabalho, as condiç̧̃es concretas da escola pública e aspectos socioculturais de sua clientela. No âmbito deste trabalho, os temas da categoria Condições Estruturais, não desenvolvidos individualmente em problemas, são considerados como o contexto onde os problemas da prática pedagógica ocorrem.

$\mathrm{Na}$ categoria "C urrículo" foi alocado um conjunto de temas relacionados às preocupações dos professores das ciências, geradas pelas reformas curriculares propostas pel os PCN s (Brasil, 1998), como, por exemplo, a questão da contextualização do conteúdo e a interdisciplinaridade. Alguns temas foram levantados apenas por professor de Física, por estarem diretamente relacionados ao conteúdo, como por exemplo, a inserção da Física M oderna no currículo, a abordagem histórica da ciência e o formalismo matemático na Física.

\section{Q uadro 2: temas extraídos do discurso dos professores de Física e de Matemática}

\begin{tabular}{|c|c|c|}
\hline Condições Estruturais & Currículo & Ensino-Aprendizagem \\
\hline $\begin{array}{l}\text { - Falta de professores na rede } \\
\text { pública } \\
\text { - Pouca motivação profissio- } \\
\text { nal dos professores } \\
\text { - D esarticulação entre os } \\
\text { professores } \\
\text { - Falta de apoio aos professo- } \\
\text { res por parte da escola } \\
\text { - Falta de cursos de capacita- } \\
\text { ção } \\
\text { - Carga horária reduzida das } \\
\text { disciplinas } \\
\text { - Infra-estrutura precária da } \\
\text { escola } \\
\text { - Falta de recursos e mate- } \\
\text { riais didáticos } \\
\text { - Não participação da famí- } \\
\text { lia na escola } \\
\text { - Baixo nível socioeconômi- } \\
\text { co e cultural do aluno }\end{array}$ & $\begin{array}{l}\text { - Seleção e adequação de } \\
\text { conteúdos } \\
\text { - Vestibular } \\
\text { - Interdisciplinaridade } \\
\text { - Contextualização do con- } \\
\text { teúdo } \\
\text { - Inovações curriculares } \\
\text { - Inserção da Física M oderna } \\
\text { - Formalismo matemático } \\
\text { - H istória da ciência } \\
\text { - Atividades extraclasse }\end{array}$ & $\begin{array}{l}\text { - M étodos tradicionais de ensi- } \\
\text { no } \\
\text { - Livro-texto } \\
\text { - Laboratório didático } \\
\text { - Tecnologias da Informação } \\
\text { e Comunicação no ensino } \\
\text { - Teorias de aprendizagem } \\
\text { - Avaliação da aprendizagem } \\
\text { - D eficiências cognitivas do } \\
\text { aluno } \\
\text { - Atitude desfavorável do } \\
\text { aluno } \\
\text { - Falta de perspectiva e inte } \\
\text { resse do aluno } \\
\text { - Indisciplina do aluno }\end{array}$ \\
\hline
\end{tabular}


Identificação de problemas do currículo, do ensino e da aprendizagem...

A categoria "Ensino-Aprendizagem" englobou temas relativos tanto a aspectos teóricos quanto práticos do trabalho dos professores. Também foi classificado nesta categoria, 0 discurso dos professores sobre as características do aluno da escola pública, como por exemplo, suas deficiências e falta de perspectiva profissional.

\section{Problemas relacionados ao C urrículo}

O s problemas identificados pela análise de avaliação de cada um dos temas da categoria Currículo são descritos resumidamente nesta seção.

D espreparo para selecionar e adequar conteúdos

Foi mencionado o despreparo do professor para selecionar e ensinar os conteúdos de forma adequada no Ensino M édio na medida em que muitos conteúdos que ele tem que dominar enquanto está se formando não são utilizados em sal a de aula. Também não há oportunidade, na formação inicial, para discutir quais os conteúdos e como estes devem ser abordados no Ensino M édio.

Dificuldades decorrentes do vestibular

O s professores manifestam a dificuldade de buscar trabalhar o conteúdo de forma diferente da tradicional (enfatizando o aspecto conceitual e tendo como único compromisso a aprendizagem) e ter de implementar um currículo que visa ao vestibular, considerado como adestramento. U m professor considera que seria possível equilibrar as duas orientações, apesar de reconhecer que não sabe como fazer isso.

D ificuldades para implementar o enfoque interdisciplinar

0 s professores valorizam o enfoque interdisciplinar e consideram que um bom curso deveria mostrar conexões com outras disciplinas. Contudo, encontram vários tipos de dificuldades para fazêlo, como por exemplo, a falta de integração entre os professores, a resistência dos professores mais antigos e a inadequação do livro-texto no que diz respeito a este enfoque.

D ificuldade para contextualizar o conteúdo

É recorrente no discurso de alguns professores a dificuldade em relacionar 0 conteúdo teórico a fenômenos do cotidiano. A associação de um conhecimento formal descontextualizado do livro-texto à realidade não se apresenta como um processo simples.

D ificuldades para implementar inovações curriculares

A referência mais importante dos professores quando são solicitados a refletir sobre o tema "Inovações Curriculares" são os PCN s. Os professores consideram os PCN s extensos e difíceis de entender e reconhecem que precisariam ser capacitados para colocálos em prática.

Por outro lado, os professores concordam com a idéia de que o currículo precisaria de mudanças e têm informações sobre metodologias inovadoras, como por exemplo, a organização do conteúdo por temas ou por projetos. Entretanto, sentem-se impotentes para promover essas mudanças individualmente, sem a participação de toda a equipe da escola. 


\section{D ificuldades para inserir a Física M oderna no currículo}

A maioria dos professores de Física reconhece que inserir a Física M oderna no currículo seria importante na medida em que o coloca em sintonia com o mundo atual. Entretanto, reconhecem que não têm a formação necessária para introduzir esse conteúdo, além de perceberem obstáculos relacionados ao currículo para implementar essa mudança, como por exemplo, a pequena carga horária da disciplina e a falta de base dos alunos.

Formalismo matemático excessivo

0 s professores de física mencionam que o aspecto matemático (formal) da física é, em geral, por demais enfatizado e que os alunos não conseguem construir o sentido deste formalismo nem relacionar teoria a experimentos físicos.

\section{Formação insuficiente para considerar a História da Ciência no ensino de Física}

U m dos professores de Física entrevistados reconheceu que a H istória da Ciência deveria fazer parte do currículo, de modo que 0 aluno compreendesse a importância dos modelos físicos e percebesse a ciência como conhecimento em constante construção e não como um conjunto de verdades absolutas. No entanto, o professor se ressente da formação insuficiente para implementar este aspecto do conteúdo no currículo.

\section{Escassez de atividades extraclasse}

O s professores de Física entrevistados comentaram que os al unos gostam de real izar atividades extraclasse, como visitas à $\mathrm{C}$ asa da Ciência ou ao Planetário. Entretanto, lamentam que este tipo de atividade não seja realizado freqüentemente, por falta de recursos da escola pública e pela necessidade de coordenação pedagógica.

\section{Problemas relacionados ao processo de Ensino-Aprendizagem}

O s problemas identificados pela análise de avaliação de cada um dos temas da categoria Ensino-Aprendizagem são resumidos nesta seção.

Insatisfação com os métodos tradicionais de ensino

O s professores estão conscientes de que ensinam de forma tradicional, mas demonstram insatisfação com seus métodos de ensino e sua prática pedagógica, seja pela falta de tempo para planejamento, por não saberem como ou por que se sentem inseguros para mudar. 0 ensino tradicional (de Física) é freqüentemente associado ao excessivo formalismo matemático.

Insuficiência do livro-texto

A maioria dos professores relata a dificuldade que têm para adotar um livro, na medida em que os alunos não têm condições para comprá-lo. Um professor mencionou que, na medida em que os alunos não compram o livro, ele tem que colocar todo o seu conteúdo no quadro-negro. Além disso, o livro-texto é considerado muitas vezes insuficiente, principalmente quando é o único material educativo utilizado.

\section{D ificuldades para usar o laboratório didático de Física}

É abordada a importância do laboratório didático de Física para demonstração dos conceitos e leis físicos, mas reconhecida a falta de tempo para preparar os experimentos e a dificuldade para desenvolver atividades que levem à efetiva aprendizagem em função do grande número de alunos por turmas. 
Identificação de problemas do currículo, do ensino e da aprendizagem...

D ificuldades para usar as tecnologias da informação e comunicação no ensino

Alguns professores reconhecem a dificuldade que têm para usar as tecnologias da informação e comunicação no ensino, apesar de considerarem importante tentar incorporálas. U m professor se cobrou esta competência e o papel de mostrar ao aluno como usá-las. A falta de recursos físicos e humanos na escola para isso também é apontada como um obstáculo para tal. 0 utros professores admitem que não gostam e que não estão interessados em usar esta tecnologia para ensinar.

D ificuldade para transpor as teorias de aprendizagem para a sala de aula

Alguns professores demonstram que têm conhecimento sobre teorias de aprendizagem, como por exemplo, o construtivismo, e valorizam sua aplicação no ensino. Entretanto, apontam a dificuldade de transpor esse conhecimento para a prática de sala de aula, alegando principalmente o número excessivo de alunos por turma.

Pouco tempo para planejamento da avaliação da aprendizagem

O s professores comparam a avaliação na escola particular, que é rígida e determinada pela direção, com a realizada na escola pública, que é muito flexível e em geral, determinada pelo professor. Entretanto, mencionam a prova com o instrumento mais utilizado, considerado o pouco tempo que podem dedicar à avaliação.

\section{D eficiências cognitivas do aluno}

Foi possível perceber que o que mais chama a atenção dos professores, quando se referem ao aluno, são as suas deficiências cognitivas, que impedem a aprendizagem. A falta de conhecimentos gerais do aluno da escola pública é motivo de preocupação dos professores de Física e de $M$ atemática, especial mente a falta de base em $M$ atemática, na medida em que esse conhecimento é pré-requisito para as duas disciplinas. Tanto os professores de Física como os de $M$ atemática mencionam também a deficiência dos alunos no que diz respeito à leitura e compreensão dos enunciados dos problemas e a dificuldade para solucioná-los em decorrência da mesma.

\section{Atitude defavorável do aluno}

0 s professores consideram a atitude do aluno em relação à Física e à M atemática, como sendo, de um modo geral, negativa, e referem-se ao quanto essa atitude impede o desenvolvimento conceitual. U m professor mencionou a dificuldade para enfrentar essa prédisposição do aluno e tentar quebrar os preconceitos.

Falta de perspectiva e de interesse do aluno

O s professores mencionam que os alunos da escola pública, hoje, de uma maneira geral, não têm interesse em aprender, pois não acreditam que a educação garanta seu futuro profissional. A perspectiva dos alunos do interior é ainda menor, restringido-se à conclusão do nível médio. N este contexto, alguns professores reconhecem que a escola pública está distante da realidade dos alunos e que precisaria mudar.

Indisciplina do aluno

Os professores se queixam do mau comportamento freqüente dos alunos hoje em dia e do acúmulo de papéis que têm que desempenhar por também terem de educá-los para o convívio social. 


\section{D iscussão dos resultados e conclusões}

Ao se confrontarem os problemas da prática pedagógica dos professores de Física e de $M$ atemática identificados com os obstáculos da prática pedagógica de professores das ciências considerados por Porlán e Rivero (1998), percebe-se que os professores estudados estão conscientes de que há problemas relacionados ao conteúdo que ensinam na medida em que se preocupam com a adequação necessária do conhecimento adquirido na formação inicial ao nível médio e a necessidade de integrar a $\mathrm{H}$ istória da Ciência ao currículo. $\mathrm{N}$ o entanto, em relação a esta questão, ainda não estão conscientes da necessidade de integração de diferentes tipos de conhecimentos (científicos, sociais, pessoais, metadisciplinares, etc.) na formulação dos conteúdos, tal qual é levantado pelos autores.

A pesar de os professores terem apontado a falta de conhecimentos gerais e matemáticos do aluno como um problema para o ensino de Física e de M atemática, as concepções espontâneas ou alternativas não foram explicitamente consideradas com parte do problema e como al go a ser levado em conta pelo professor na sua prática pedagógica. Este seria um ponto a ser explorado em processos de formação continuada.

A introdução do processo investigativo na prática do professor (Porlán e Rivero, 1998) não foi alvo da preocupação dos professores entrevistados, o que leva a percepção de que os professores não valorizam a obtenção de informações sobre o desenvolvimento de uma determinada intervenção curricular.

A pesquisa confirmou as dificuldades de se implementarem mudanças coletivas na prática docente devido ao currículo (Allain, 2000, citado por M enezes eVaz, 2002) e ao isolamento do professor e as dificuldades para utilizar materiais didáticos diferentes do livrotexto, o laboratório didático e as tecnologias da informação e comunicação (Vianna e Araújo, 2002).

Foi possível concluir que professores de Física e de M atemática da escola pública enfrentam, em geral, problemas pedagógicos semelhantes, o que pode estar relacionado às condições de trabalho comuns. 0 s problemas curriculares estão marcados pelas políticas educacionais atuais e os de ensino-aprendizagem dizem respeito tanto a aspectos teóricos quanto práticos do trabal ho dos professores, além de exprimirem queixas em relação às deficiências de vários tipos do aluno da escola pública. 0 s professores não demonstraram uma visão crítica em relação aos PCN s e se sentem mal por não terem as condições para implementá-los. M uitos dos problemas de ensino-aprendizagem atribuídos ao aluno podem estar escondendo a responsabilidade do professor por sua aprendizagem.

Alguns dos problemas da prática pedagógica dos professores entrevistados são objeto de estudo da pesquisa em ensino de Ciências, outros não são, o que indica um certo desencontro entre a produção acadêmica e a realidade da escola pública. Alguns podem ser generalizados para escola particular, outros não. A continuidade dessa investigação pode indicar em que medida os problemas identificados estão relacionados às condições de trabalho diferentes das redes privada e pública e às concepções (implícitas e explícitas) dos professores.

0 s problemas identificados constituirão a referência para a narrativa de situaçõesproblema oferecidas no InterAge, cujas propostas de solução por professores-usuários do ambiente, com base nos recursos tecnológicos e pedagógicos oferecidos, são a motivação de um processo de formação continuada à distância. Espera-se que a autenticidade dos problemas levantados leve professores de Física e de M atemática da rede pública de outros Estados do Brasil, que terão acesso ao ambiente virtual, a se identificarem e crie neles a "necessidade sentida" de buscar soluções. 
$\mathrm{N}$ ão há como negar a tensão entre o processo de formação continuada dos professores da rede pública e suas difíceis condições de trabalho. É necessário, por um lado, buscar a adequação e a relevância da pesquisa e da formação continuada a ser oferecida a esses professores, mas por outro, não deixar que essa especificidade se torne limitadora do potencial que eles apresentam. 0 caminho mais promissor para todos os envolvidos com a formação de professores parece ser investir o máximo na formação continuada dos professores e, ao mesmo tempo, lutar politicamente para melhoria da educação pública brasileira.

0 estudo dos problemas da prática pedagógica de professores da escola pública indicou que, do ponto de vista das políticas educacionais, seria importante que a melhoria das condições estruturais de funcionamento da escola pública e das condiç̧ões de trabal ho dos professores fosse tão prioritária quanto a elaboração de diretrizes curriculares inovadoras, na medida em que a falta de investimentos nas condições concretas da educação compromete as ações e avanços de ordem pedagógica, quaisquer que sejam as propostas.

\section{Referências}

BARDIN, L. Análise de conteúdo. Lisboa: Edições 70, 1977.

BARRows, H. S.; TAM BLYN, R. M. Problem-based learning: an approach to medial education. N ew York:

Springer; 1980.

BRASIL. M inistério de Educação e do D esporto. Parâmetros Curriculares N acionais bases legais Braślia: M EC, 1998. CAPRARA, A. A construção narrativa de problemas. In: M AM EDE, S. et al. (O rg.) Aprendizagem baseada em proble mas: anatomia de uma nova abordagem educacional. Fortaleza: Hucitec, 2001.

GIBSON, P. R. Problem based learning as a multimedia design. Journal of Technology and Teacher Education, Norfolk, v. 8, n. 4, 2000.

Graeber, W.; Buender, W.; NenTWIG, P. From academic knowledge to PCK: the need for transformation and

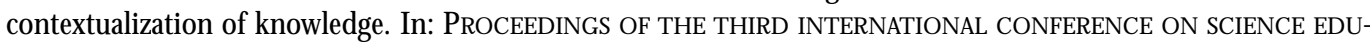
Cation ReSEARCh IN The KN OWLedge based so Ciety. 3., 2001, Thessal oniki. Proceedings... Thessaloniki: Art of Text, 2001.

JONASSEN, D. D esigning constructivist learning environments. In: REIGELUTH, C. M . (Ed.). Instructional theories and models. 2. ed. M ahwah: Lawrence Erlbaum, 1998.

. Instructional design models for well-structured and ill-instructed problem solving learning outcomes.

Educational Technology Research \& Development, Washington, v. 45, n. 1, p. 65-94, 1997.

. 0 uso das novas tecnologias na educação a distância e a aprendizagem construtivista. Em Aberto,

Brasília, v. 16, n. 70, abr./jun., 1996.

Ko m ATSU, R. S. et al. Aprendizagem baseada em problemas. In: M ARCONDES, E.; G On çALVES, E. L. (O rg.).

Educação médica. São Paulo: Sarvier, 1998.

KRUGER, V. Evolução das concepções de professores de ciências e de matemática sobre metodologia; análise de um caso. In: EN CONTRO NACIONAL DE PESQUISA EM ENSIN O DE CIÊNCIAS, 3., 2001, Atibaia. Atas... Atibaia: [s. n.], 2001.

M ENEZES, P. H .; V AZ, D . A. A tradição e inovação no ensino de física e a influência na formação e profissionalização docente. In: EN CONTRO DE PESQUISA EM EN SINO DE FísICA, 8., 2002, Águas de Lindóia. Atas... Águas de Lindóia: [s. n.], 2002.

PONTE, J. P. Didácticas específicas e construção do conhecimento profissional. In: CONGRESSO DA SO CIEDADE PORTUGUESA DE CIÊNCIAS DE EDUCAÇÃo, 4., 1998. Atas... Aveiro: SPCE, 1998.

Porlán, R.; Rivero, A. El conocimiento de los professores: uma propuesta formativa en el área de ciencias. Sevilla: Diada, 1998.

ReZEN DE, F. As novas tecnologias na prática pedagógica sob a perspectiva construtivista. Ensaio - Pesquisa em Educação em Ciências. Belo H orizonte, v. 2, n. 1, p. 75-98, 2000.

REZEN DE, F. et al. InterAge: um ambiente virtual construtivista para formação continuada de professores de Física. Caderno Brasileero de Ensino de Física, Florianópolis, v. 20, n. 3, p. 372-390, 2003. 
SAVERY, J. R.; D ufFY, T. M. Problem based learning: an instructional model and its constructivist framework. Educational Technology, Englewood, p. 31-37, set.-oct. 1995.

SCH NETZLER, R. P. 0 professor de ciências: problemas e tendências de sua formação. In:

SChnetZler, R. P.; Aragão, R. M. R. (O rg.). Ensino de ciências: fundamentos e abordagens. Campinas: UN IMEP, 2000.

SCHÖN, D. Educando o profissional reflexivo. Porto Alegre: Artes M édicas, 2000.

STRUCHINER, M . et al. Elementos fundamentais para o desenvolvimento de ambientes construtivistas de aprendizagem a distância. Tecnologia Educacional, Rio de Janeiro, v. 26, n. 142, p. 3-11, 1998.

Vian Na, D. M.; ARAújo, R. S. UniEscola: dando apoio aos professores de física. EN CONTRO DE PESQUISA EM ENSINO DE FísICA, 8., 2002. Atas... Águas de Lindóia: [s. n.], 2002.

\section{Artigo recebido em dezembro de 2003 e} selecionado para publicação em julho de 2004. 